\title{
Imaging neuroinflammation in multiple sclerosis using TSPO-PET
}

\author{
Laura Airas $^{1,2} \cdot$ Eero Rissanen ${ }^{1,2} \cdot$ Juha O. Rinne ${ }^{1,2}$
}

Received: 27 August 2015/Accepted: 22 September 2015/Published online: 19 October 2015

(C) Italian Association of Nuclear Medicine and Molecular Imaging 2015

\begin{abstract}
Conventional MR imaging (MRI) techniques form the cornerstone of multiple sclerosis (MS) diagnostics and clinical follow-up today. MRI is sensitive in demonstrating focal inflammatory lesions and diffuse atrophy. However, especially in progressive MS, there is increasingly widespread diffuse pathology also outside the plaques, often related to microglial activation and neurodegeneration. This cannot be detected using conventional MRI. Positron emission tomography (PET) imaging using $18-\mathrm{kDa}$ translocator protein (TSPO) binding radioligands has recently shown promise as a tool to detect this diffuse pathology in vivo, and for the first time allows one to follow its development longitudinally. It is becoming evident that the more advanced the MS disease is, the more pronounced is microglial activation. PET imaging allows the detection of MS-related pathology at molecular level in vivo. It has potential to enable measurement of effects of new disease-modifying drugs aimed at reducing neurodegeneration and neuroinflammation. PET imaging could thus be included in the design of future clinical trials of progressive MS. There are still technical issues related to the quality of TSPO radioligands and post-processing methodology, and comparison of studies from different PET centres is challenging. In this review, we summarise the main evidence supporting the use of TSPO-PET as a tool to explore the diffuse inflammation in MS.
\end{abstract}

Laura Airas

laura.airas@utu.fi

1 Division of Clinical Neurosciences, Turku University Hospital, Kiinamyllynkatu 4-8, 20521 Turku, Finland

2 Turku PET Centre, Turku University Hospital and University of Turku, Turku, Finland
Keywords Multiple sclerosis - Microglia · Imaging · Progressive disease

\section{Introduction}

Multiple sclerosis (MS) is an autoimmune disease of the central nervous system (CNS), where neuroinflammation and neurodegeneration are the two main components in the pathogenesis. Even though the fundamental cause of the disease is not entirely understood, several environmental and genetic predisposing factors have been identified. The clinical presentation of MS is heterogeneous, with the most typical form at the onset of the disease being relapsingremitting MS (RRMS) which is characterised by acute worsenings of neurological symptoms followed by a full or partial recovery. RRMS shifts into secondary progressive MS (SPMS) on average 10 years after disease onset, and slowly cumulating symptoms lead to irreversible and progressive disability [1].

The inflammatory activity in RRMS can be suppressed with disease-modifying therapies; these can reduce the number of relapses, and the progression of the disease can be slowed down to some extent [2]. Tragically, there is no curative treatment for MS and moreover, no effective treatment is available to prevent the cumulative disability in the progressive forms of the disease. Being the most common disability causing neurological disease in young adults [3], the socioeconomic impact of MS is considerable both in terms of individual suffering and its burden on the health service budget $[1,4]$. Thus, more research is clearly needed to understand the pathophysiology, to develop alternative biomarkers for the evaluation of disease activity, and to seek alternative pathways for therapeutic development in the treatment of progressive MS. 
According to current understanding, both neuroinflammation and neurodegeneration occur during all stages of MS [3, 5-7]. Axonal loss underlies especially the transition from relapsing to progressive MS, but neurodegeneration with axonal transections is known to be present already early in the disease $[1,8]$. By studying progressive MS, one may thus gain important insights about the degenerative component of MS present in all stages of the disease.

MR imaging (MRI) remains the cornerstone of modern clinical diagnostics and follow-up of inflammatory activity and gross atrophy related to MS. However, MRI does not allow examination of the specific molecular pathophysiology and neuroreceptor binding related to MS pathology. Positron emission tomography (PET) imaging on the other hand enables molecular and neuroreceptor imaging in vivo. Particularly relevant for the study of MS is PET imaging of activated microglia. Here, several radioligands binding to the $18 \mathrm{kDa}$ translocator protein (TSPO) - a protein structure expressed on the outer mitochondrial membrane of activated, but not resting microglia—have been developed [9].

\section{Microglia in MS}

Microglia are myeloid cells of the central nervous system (CNS), that are derived from early embryonic erythromyeloid progenitor cells and have migrated into the developing nervous tissue, where they have begun the maturation process into brain-resident microglial cells [10]. Microglia constitute approximately 10 percent of the total cell population in a human brain. The key tasks performed by microglia include phagocytosis of extracellular debris, antigen presentation to host immune cells, and secretion of inflammatory mediators [11].

In the early phase of MS, microglial activation promotes the recruitment of naïve $T$ cells, which are activated in the periphery by dendritic cells functioning as antigen-presenting cells. Microglia also act as antigen-presenting cells, re-stimulating the auto-reactive memory-T-cells invading through the blood-brain barrier (BBB) into the CNS. This is considered a key event in maintaining the chronic inflammation in the CNS [12, 13]. In active white matter lesions, there is a profound infiltration of activated microglia and blood-borne macrophages throughout the lesion, whereas in slowly expanding (smouldering) or chronic active lesions, the microglia and macrophages are concentrated as a dense rim around the lesions [6, 14]. Microglia have also been found diffusely in white and gray matter with concomitant axonal degeneration and meningeal inflammation. Thus, chronic activation of microglia has been linked to neurodegeneration in the progressive phase of the disease [15-17]. In progressive MS disease, activation of microglia has been detected in areas of the brain which appear normal in conventional MRI, the socalled normal appearing white matter (NAWM) [5, 6].

When microglia are activated following an insult, they become mobile and capable of phagocytosis and antigen presentation. The phagocytosis of debris by microglia is thought to be essential for enabling the return of normal tissue homeostasis after an insult. In chronic neuroinflammation, the equilibrium between debris-clearing and inflammation-propagating microglia becomes unbalanced, and the overactivated microglia cause uncontrolled neuronal damage resulting in a self-propagating vicious cycle and progressive neurodegeneration [18]. It is thus possible that prolonged inflammation related to activated microglial cells is one of the driving forces of the chronic progression of MS disease. Presently, the differentiation between activated brain-resident microglia and blood-derived macrophages-which may possess different functions-is challenging, and might distort the interpretation of in vitro and in vivo studies on the role of microglia in health and disease. Notwithstanding the lack of understanding the exact role of the myeloid cells in the different stages of MS pathogenesis, the presence of activated microglia is well established in the MS brain.

\section{TSPO and activated microglia}

Activated microglia express the TSPO, earlier called the peripheral benzodiazepine receptor (PBR) on the outer membrane of mitochondria. Several functions have been attributed to TSPO, either directly or indirectly, including immunomodulation, regulation of cholesterol transport, synthesis of steroid hormones, apoptosis, cell proliferation, porphyrin and anion transport, regulation of mitochondrial functions and heme synthesis [19]. Structurally, TSPO is an $18 \mathrm{kDa}$ macromolecular protein with a structure of five alpha helices spanning the membrane lipid bilayer. Two archetypal ligands binding to TSPO have been identified, namely Ro5-4864, the 4-chloro-derivative of diazepam, and PK11195, the isoquinoline carboxamide [20], the latter having been used as a marker for in vivo PET imaging of activated microglia.

Whereas TSPO is highly expressed in activated microglia, in the "resting" or surveying microglia, it is expressed at a lower level, and mainly in the gray matter [21]. As a marker of microglial activation, TSPO expression has been shown to be increased in many cerebral pathological states, such as Huntington's disease (HD) [22], brain ischemia [23] and MS [24]. In Parkinson's disease (PD) and Alzheimer's disease (AD), some neuropathological studies have found evidence of increased microglial activation [25], in line with the in vivo findings of increased TSPO 
binding in some studies of PD [26, 27] and $\mathrm{AD}[28,29]$. In addition, TSPOs are highly expressed in gliomas [30, 31], with the majority of the expression being accounted for by tumour cells instead of microglia [32]. More in-depth reviews on the role of TSPO in disease pathologies of AD, $\mathrm{PD}$ and glioma are also presented in this special issue. In non-neoplastic CNS damage without BBB breakdown, microglia are the main cell population expressing TSPO [33]. In focal damage with BBB breakdown, also TSPO expressing activated macrophages-cells which have invaded from the peripheral blood into brain parenchyma-are present [34]. Taken together, TSPO upregulation on microglial cells is considered to be a sensitive "real-time" marker of neuroinflammation and neuronal injury, reflecting mainly microglial activity, and to some extent reactive astrocytes $[35,36]$.

\section{TSPO-PET ligands in MS studies}

TSPO has been the most widely used target in the PET imaging of neuroinflammation. For more than 25 years, the prototypic TSPO radioligand in use has been $\left[{ }^{11} \mathrm{C}\right] \mathrm{PK} 11195$, with the first human brain studies conducted in patients with glioma [37], Rasmussen's encephalitis [38], and in healthy controls and MS patients [24]. The use of $\left[{ }^{11} \mathrm{C}\right] \mathrm{PK} 11195$ in clinical studies has been somewhat impeded due to its relatively low signal-to-noise ratio [39] despite of its high specificity for TSPO [40]. The low signal-to-noise ratio leads to uncertainty about the proportion of specific (displaceable) binding, which complicates accurate modelling of the signal. This characteristic has been attributed to the ligand's rather low penetration through the BBB [9], as well as to the ligand's binding to structures in the brain vasculature, where endothelial and smooth muscle cells also express TSPO [35]. Reactive astrocytes are also known to overexpress TSPO in response to injury [41] probably adding to the non-microglial specific binding [42, 43]. In addition, instead of $\left[{ }^{11} \mathrm{C}\right](\mathrm{R}) \mathrm{PK} 11195$, the earliest studies [24, 37] used the racemic mixture of $\left[{ }^{11} \mathrm{C}\right] \mathrm{PK} 11195$ - which is also a confounding factor when comparing the older and newer studies. Another challenge related to MS studies and the TSPO ligands is the lack of anatomically clearly defined reference region devoid of specific binding. This is particularly relevant in neuroinflammatory and neurodegenerative diseases with diffusely dispersed pathologies—such as in MS. Quantitative analytical techniques, either using the input function from arterial sampling or reference regions extracted by supervised clustering algorithms, have been developed for signal quantification. To overcome the lack of a suitable reference region, an automated method for the supervised clustering of normal gray matter reference for $\left[{ }^{11} \mathrm{C}\right](\mathrm{R})$-PK11195 PET images has been developed (SuperPK software; Imperial College, London, UK) [44-46]. Briefly, in this methodology, a set of predefined kinetic tissue class time-activity curves (TACs), representing the average kinetics of the radiotracer in different types of brain tissue is first created. Thereafter, a weighted linear combination of tissue class TACs is fitted to each voxel-wise TAC of the dynamic PET image, which is standardised using frame-wise means and standard deviations [46]. Consequently, a weight coefficient for each PET image voxel, that represents the contribution of each kinetic class to the corresponding TAC, is provided. This methodology has already been successfully applied in patients with Alzheimer's disease [44, 46] and MS [47-49].

Numerous second-generation TSPO radioligands with higher affinity and specificity than their predecessor $\left[{ }^{11} \mathrm{C}\right](\mathrm{R})-\mathrm{PK} 11195$ have been developed $[9,50]$. However, the utility of second-generation TSPO ligands in clinical studies in humans has so far been hampered by these ligands' mixed affinity binding phenotype, which has recently been discovered to be attributed to TSPO gene polymorphism in humans [51], a phenomenon, however, not affecting $\left[{ }^{11} \mathrm{C}\right](\mathrm{R})-\mathrm{PK} 11195$ binding. A single nucleotide polymorphism (22q13.2 rs6971) in the TSPO gene leads to a replacement of cytosine (C) with thymidine (T) leading to alanine being replaced with threonine in position 147 in the protein. This in turn leads to three different phenotypes with regard to the TSPO binding affinity: low affinity binders (LAB; T/T; threonine/threonine homozygote), mixed affinity binders, (MAB; C/T, alanine/threonine heterozygote) and high affinity binders (HAB; C/C, alanine/alanine homozygote), of which HAB is the most common phenotype $(49 \%)$ in a Caucasian population, followed by MAB (42\%) and LAB (9 \%) [51]. In $\mathrm{LAB}$ subjects, the binding of the second-generation TSPO ligands in the brain is too low to permit a reliable quantification of activated microglia with PET $[52,53]$. However, if the binding class is known a priori, then the LAB subjects can be excluded, and subsequently the results stratified according to $\mathrm{MAB}$ and $\mathrm{HAB}$ groups; then, the within-subject variability of the second-generation ligands is significantly lower than can be achieved with $\left[{ }^{11} \mathrm{C}\right](\mathrm{R})$ PK11195. Consequently, the sample sizes needed to reveal $50 \%$ differences in between-group analyses would be approximately half of those needed with $\left[{ }^{11} \mathrm{C}\right](\mathrm{R})$ PK11195 [54]. To acquire the binding class information, one must perform peripheral blood sampling to allow genetic testing of the TSPO polymorphism. In addition, despite their better signal-to-noise ratio than $\left[{ }^{11} \mathrm{C}\right](\mathrm{R})$ PK11195, the second-generation TSPO ligands have also been shown to bind to reactive astrocytes $[55,56]$. 


\section{TSPO-PET studies of relapsing MS patients}

\section{$\left.{ }^{11} \mathrm{C}\right](\mathrm{R})-\mathrm{PK} 11195$}

PET imaging of activated microglia with TSPO-binding radioligands is being increasingly utilised in MS research. The first in vivo TSPO-PET pilot study in MS patients with $\left[{ }^{11} \mathrm{C}\right]$ (R)-PK11195 revealed that TSPO binding was increased in acute lesions but was low in chronic lesions [24]. Thereafter, another study detected a pattern of increased TSPO binding in scattered areas related to demyelinating lesions in MRI (excluding black holes) and also in NAWM and central gray matter (thalami and brainstem); the majority of the subjects in the study were RRMS patients [34]. Subsequently, Debruyne and colleagues $[57,58]$ reported that TSPO binding was elevated in gadolinium-enhancing active plaques, and in non-enhancing $\mathrm{T} 2$ lesions during relapse, when compared to T2 lesions in patients without relapse. However, the T2 lesional binding was at a similar or lower level than in NAWM. Interestingly, the TSPO binding in the NAWM showed an increasing trend associating to longer disease duration. The patient characteristics in these early studies were heterogeneous, with patients representing both RRMS and SPMS as well as primary progressive (PPMS) clinical subtypes of the disease. Further analyses by the same group showed that increasing brain atrophy was associated with higher TSPO binding in NAWM but lower binding in T2 lesional brain [59].

The effect of disease-modifying treatment on microglial activation has been evaluated in only one MS study. In this study, 1-year treatment of RRMS with glatiramer acetate reduced TSPO binding significantly in both cortical GM and cerebral WM when compared to cerebellum [59]. Politis and colleagues demonstrated increased $\left[{ }^{11} \mathrm{C}\right](\mathrm{R})$ PK11195 binding in the cerebral cortex and in the white matter in both SPMS and RRMS patients when compared to healthy controls. Moreover, the cortical TSPO binding correlated with the clinical disability, the correlation being more evident in patients with SPMS than in those with RRMS. Similar correlation was not found for WM [47]. In another study, the total TSPO binding in the NAWM predicted the conversion of clinically isolated syndrome (CIS) to RRMS [61]. Tables 1 and 2 list all MS studies performed so far using the radioligand $\left[{ }^{11} \mathrm{C}\right](\mathrm{R})-\mathrm{PK} 11195$.

\section{Second-generation TSPO radioligands}

Until today, only few studies with second-generation TSPO ligands have been performed in MS patients in vivo. The inability of $\left[{ }^{11} \mathrm{C}\right]$ PBR28 2 and $\left[{ }^{18}\right]$ FEDAA1106 to reveal differences in the TSPO binding in WM or GM between healthy controls and MS patients in the studies by $\mathrm{Oh}$ and colleagues [62] and Takano et al. [63], respectively, is most likely explained by the high variation in the specific binding caused by the TSPO gene polymorphism, since the role of this genetic variation in TSPO binding was not established until recently [51]. The study by $\mathrm{Oh}$ et al. found that the ratio of WM to GM uptake of $\left[{ }^{11} \mathrm{C}\right] \mathrm{PBR} 28$ was increased in RRMS in comparison to healthy controls. Similarly, $\left[{ }^{11} \mathrm{C}\right] \mathrm{PBR} 28$ binding was also increased in gadolinium-enhancing active plaques [62]. Interestingly, in some lesions, a focal increase in $\left[{ }^{11} \mathrm{C}\right] \mathrm{PBR} 28$ binding preceded the appearance of gadolinium enhancement, pointing to a role for early glial activation in MS lesion development [62]. Another pilot study with 4 RRMS patients detected similar patterns of TSPO binding with the second-generation TSPO ligand $\left[{ }^{11} \mathrm{C}\right]$ vinpocetine when compared to $\left[{ }^{11} \mathrm{C}\right](\mathrm{R})-\mathrm{PK} 11195$, but with higher binding potentials and a better signal-to-noise ratio [64]. Importantly, a recent test-retest study with $\left[{ }^{11} \mathrm{C}\right] \mathrm{PBR} 28$ on healthy controls and RRMS patients showed good reproducibility of the ligand's distribution volume $\left(\mathrm{V}_{\mathrm{T}}\right)$ estimates in WM and GM as well as in focal MS lesions with a test-retest variability of 7-9\% [64, 65]. Another test-retest study with $\left[{ }^{11} \mathrm{C}\right] \mathrm{PBR} 28$ on healthy controls [66] showed higher mean absolute variability in $\mathrm{V}_{\mathrm{T}}$ in $\mathrm{GM}$ (13.8-25.9\% depending on the region). However, the intraclass reliability, measured with intraclass correlation coefficient (ICC) was high, with ICC ranging from 0.90 to 0.94 in the GM regions, and with no significant differences between the MAB and HAB subgroups. In accordance with the results with $\left[{ }^{11} \mathrm{C}\right] \mathrm{PBR} 28$, a study with $\left[{ }^{18} \mathrm{~F}\right] \mathrm{PBR} 111$ [67], where the subjects were matched according to their TSPO binding genotype, showed that the TSPO binding was increased in the T2 lesional and perilesional WM of RRMS patients $(n=11)$ when compared to healthy controls $(n=11)$, and the ratio of $\mathrm{V}_{\mathrm{T}}$ in the T2-lesional $\mathrm{WM}$ versus NAWM appeared to correlate with the disease severity (measured with the multiple sclerosis severity scale, MSSS).

These results suggest that TSPO-PET could be used for monitoring pharmacological effects targeting neuroinflammation. Moreover, with the stratification of study subjects according to the TSPO binding phenotype now being feasible with simple PCR testing [51], it is probable that the second-generation TSPO ligands will be utilised increasingly in MS studies.

\section{TSPO-PET studies of progressive MS patients}

The ability to detect activated microglial cells/macrophages related to focal inflammatory lesions using TSPOPET takes MS imaging a step forward from MRI imaging in terms of specificity. MRI detects mostly changes in 
Table 1 Summary of study design and study population characteristics in $\left[{ }^{11} \mathrm{C}\right] \mathrm{PK} 11195$ PET MS studies

\begin{tabular}{|c|c|c|c|c|c|c|c|c|}
\hline & Study design & $\begin{array}{l}\text { Disease or } \\
\text { subgroup } \\
\text { type }(n)\end{array}$ & $\begin{array}{l}\text { Age } \\
\text { Mean (SD) } \\
\text { years }\end{array}$ & $\begin{array}{l}\text { Disease } \\
\text { duration } \\
\text { Mean (SD) } \\
\text { years }\end{array}$ & $\begin{array}{l}\text { EDSS } \\
\text { Mean (SD) }\end{array}$ & $\operatorname{DMT}(n)$ & $\begin{array}{l}\text { relapse } \\
\text { during } \\
\text { scan }(n)\end{array}$ & $\begin{array}{l}\text { Patients with } \\
\text { Gd + lesions } \\
(n)\end{array}$ \\
\hline $\begin{array}{l}\text { Vowinckel } \\
\text { et al. [24] }\end{array}$ & $\begin{array}{l}\text { Cross } \\
\text { sectional }\end{array}$ & RRMS (2) & $\mathrm{np}$ & np & np & np & $0^{\alpha}$ & $0^{a}$ \\
\hline \multirow{3}{*}{$\begin{array}{l}\text { Banati } \\
\text { et al. [34] }\end{array}$} & \multirow{3}{*}{$\begin{array}{l}\text { Cross } \\
\text { sectional }\end{array}$} & RRMS (8) & $41.3(13.1)$ & $8.3(7.5)$ & $3.1(0.9)$ & IFN- $\beta$ (1) & 1 & $\mathrm{np}$ \\
\hline & & SPMS (1) & 53.0 (na) & 9.0 (na) & 7.0 (na) & & & \\
\hline & & PPMS (3) & $53.0(11.0)$ & $6.7(4.2)$ & $5.2(1.5)$ & & & \\
\hline \multirow{4}{*}{$\begin{array}{l}\text { Debruyne } \\
\text { et al. [57] }\end{array}$} & \multirow{4}{*}{$\begin{array}{l}\text { Cross } \\
\text { sectional }\end{array}$} & $\mathrm{HC}(7)$ & $33.0(8.0)$ & $7.7(7.9)$ & $2.7(1.5)$ & IFN- $\beta(4)^{*}$ & 5 & 8 \\
\hline & & RRMS (13) & 36.7 (7.4) & $14.1(10.0)$ & $5.6(1.1)$ & & 1 & 2 \\
\hline & & SPMS (7) & $50.6(9.5)$ & $13.2(0.7)$ & $6.5(0.7)$ & & 0 & 0 \\
\hline & & PPMS (2) & $54.5(13.4)$ & & & & & \\
\hline \multirow{4}{*}{$\begin{array}{l}\text { Versijpt } \\
\text { et al. [59] }\end{array}$} & \multirow{4}{*}{$\begin{array}{l}\text { Cross } \\
\text { sectional }\end{array}$} & $\mathrm{HC}(8)$ & $37.2(13.0)$ & 7.7 (7.9) & $2.7(1.5)$ & IFN- $\beta(4)^{*}$ & $6^{*}$ & $10^{*}$ \\
\hline & & RRMS (13) & 36.7 (7.4) & $14.1(10.0)$ & $5.6(1.1)$ & & & \\
\hline & & SPMS (7) & $50.6(9.5)$ & $13.2(0.7)$ & $6.5(0.7)$ & & & \\
\hline & & PPMS (2) & $54.5(13.4)$ & & & & & \\
\hline \multirow{2}{*}{$\begin{array}{l}\text { Ratchford } \\
\text { et al. [60] }\end{array}$} & \multirow{2}{*}{$\begin{array}{l}\text { Treatment } \\
\text { study }\end{array}$} & RRMS (9) & Median 51 & Median 5.3 & Median 2.0 & GA & 0 & $n p^{£}$ \\
\hline & & & Range (25-62) & Range $(0.5-21)$ & Range (1.0-6.0) & & & \\
\hline \multirow{3}{*}{$\begin{array}{l}\text { Politis et al. } \\
\text { [48] }\end{array}$} & \multirow{3}{*}{$\begin{array}{l}\text { Cross } \\
\text { sectional }\end{array}$} & $\mathrm{HC}(8)$ & 32.9 (4.6) & - & - & $\mathrm{np}$ & $\mathrm{np}$ & $n p^{\S}$ \\
\hline & & RRMS (10) & $36.8(8.4)$ & $11.1(8.0)$ & $5.5(1.4)$ & & & \\
\hline & & SPMS (8) & $40.4(11.1)$ & $17.0(11.1)$ & $7.4(1.2)$ & & & \\
\hline \multirow{3}{*}{$\begin{array}{l}\text { Giannetti } \\
\text { et al. [47] }\end{array}$} & \multirow{3}{*}{$\begin{array}{l}\text { Cross } \\
\text { sectional }^{\&}\end{array}$} & RRMS (10) & $38.3(8.5)$ & $12.6(7.3)$ & $5.3(1.5)$ & IFN- $\beta$ (2), & 0 & 0 \\
\hline & & $\operatorname{PMS}(9)^{\#}$ & $39.2(11.1)$ & $15.8(10.5)$ & $7.3(1.2)$ & GA (1) & & \\
\hline & & & & & & $\begin{array}{l}\text { CP (1), } \\
\text { GA (1) }\end{array}$ & & \\
\hline \multirow{2}{*}{$\begin{array}{l}\text { Rissanen } \\
\text { et al. [49] }\end{array}$} & \multirow{2}{*}{$\begin{array}{l}\text { Cross } \\
\text { sectional }\end{array}$} & $\mathrm{HC}(8)$ & $49.7(10.5)$ & $13.3(6.3)$ & $6.3(1.5)$ & None & 0 & 5 \\
\hline & & SPMS (10) & $49.8(7.9)$ & & & & & \\
\hline \multirow{2}{*}{$\begin{array}{l}\text { Giannetti } \\
\text { et al. [61] }\end{array}$} & \multirow{2}{*}{$\begin{array}{l}\text { Cross } \\
\text { sectional }^{\&}\end{array}$} & $\mathrm{HC}(8)$ & $30.2(5.5)$ & $0.4(0.2)$ & $1.7(1.0)$ & None & 0 & $\mathrm{np}$ \\
\hline & & CIS (18) & $38.5(7.8)$ & & & & & \\
\hline
\end{tabular}

EDSS expanded disability status scale, RRMS relapsing-remitting multiple sclerosis, SPMS secondary progressive multiple sclerosis, $P P M S$ primary progressive multiple sclerosis, $H C$ healthy control, PMS (progressive multiple sclerosis), $C I S$ clinically isolated syndrome, $n p$ information not provided, $D M T$ disease-modifying treatment, $I F N-\beta$ beta-interferon, $G A$ glatiramer acetate (initiated after baseline imaging), $C P$ cyclophosphamide, $G A$ glatiramer acetate

One patient with a relapse 4 weeks prior to scan, resolving acute lesion in MRI at the time of PET scan

* Of all patients, disease subtype not specified

${ }^{£}$ Median number (range) of gadolinium-enhancing lesions at baseline: 0 (0-15)

$\S$ Median volumes of gadolinium-enhancing lesions: RRMS $144 \mathrm{~mm}^{3}$, SPMS $89 \mathrm{~mm}^{3}$

\# 8 SPMS patients and 1 PPMS patient pooled into one group of PMS patients

\& Longitudinal follow-up for clinical parameters

water content in the pathological tissues, but with molecular imaging can one detect specific cell types, depending on the specificity of the radioligand in use. It is known from neuropathology studies, that in SPMS and in PPMS there is a diffuse, widespread inflammatory process within the CNS with activation of microglial cells also outside plaque areas, which is closely associated with axonal damage [6]. This diffuse inflammation cannot be detected using conventional MRI, but with careful modelling, it can be quantified in vivo using TSPO-PET. The impact of TSPO-PET imaging and the unique opportunity it gives by allowing in vivo visualisation of the functional change of a cell within the brain that has a major role in the pathology of MS is only beginning to be appreciated. In PPMS, TSPO-PET studies are still mostly lacking, but it has been clearly demonstrated in in vivo studies that $\left[{ }^{11} \mathrm{C}\right]-\mathrm{PK} 11195$ binding in the NAWM of SPMS is significantly increased when compared to age-matched healthy controls [34, 48, $49,57]$. In these studies, all focal inflammatory lesions have been carefully masked out, and the tissue of interest comprises areas appearing normal in MRI. Hence, in this application, TSPO-PET is providing truly complementary 


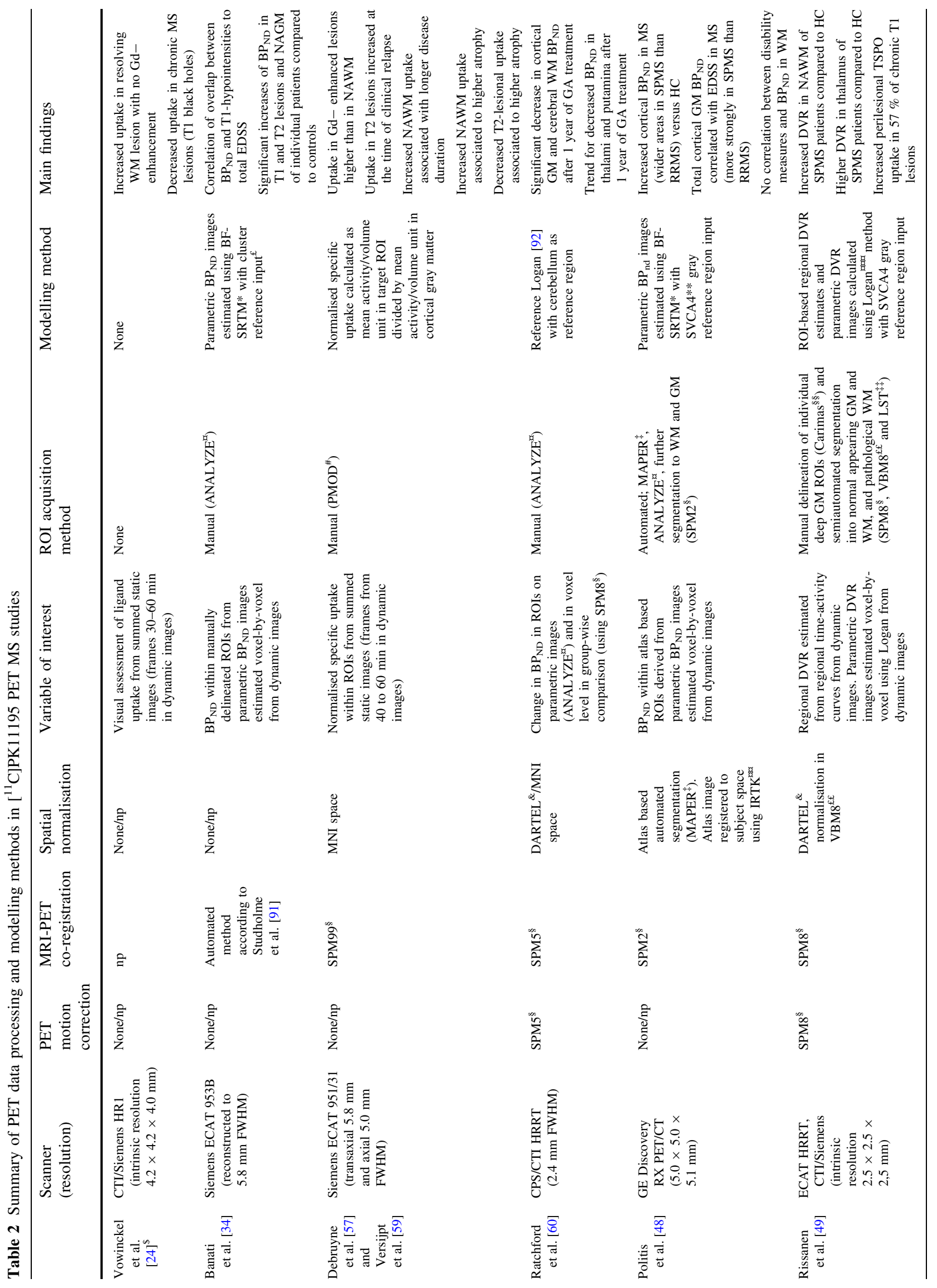




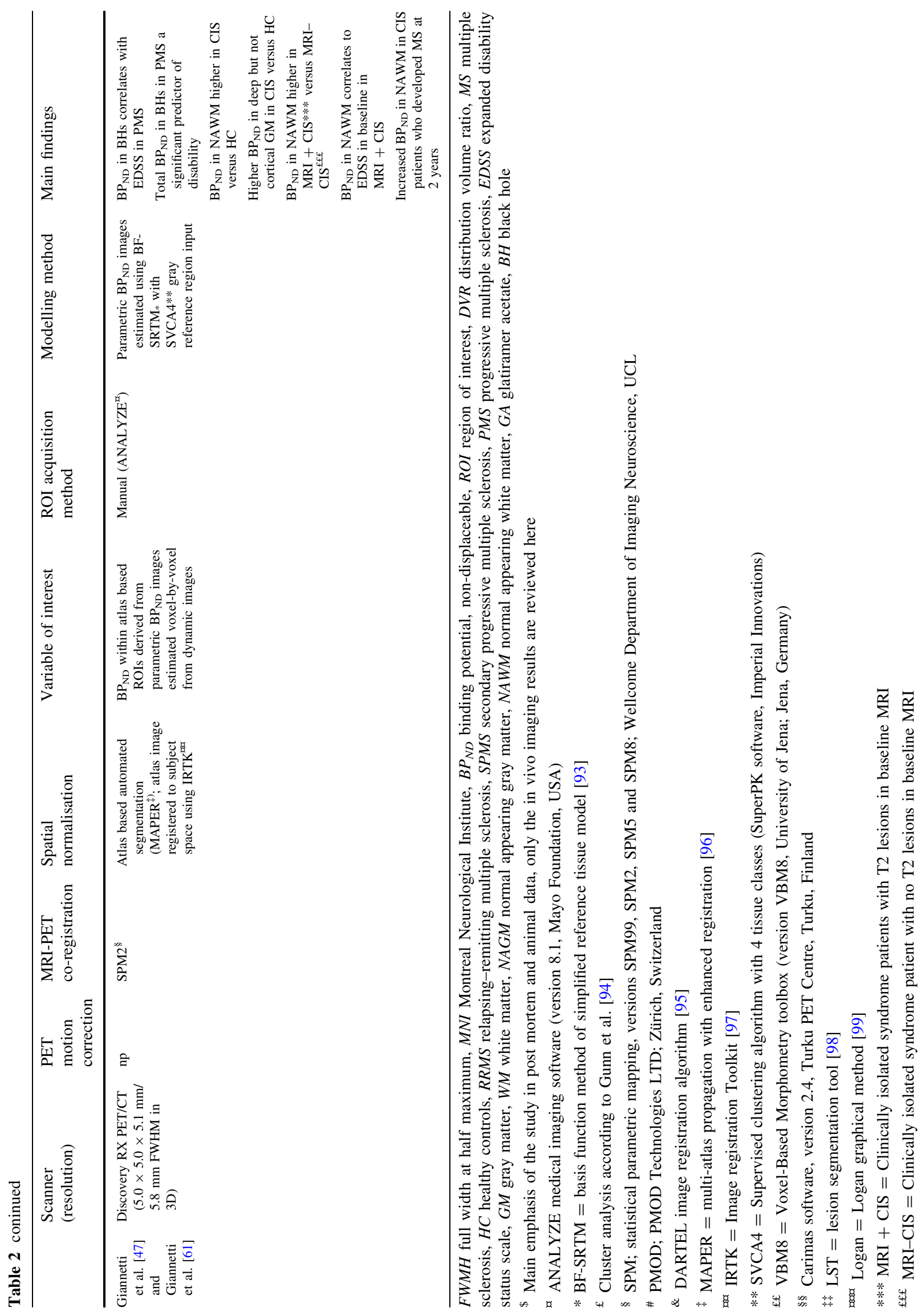


information to MRI. Moreover, our preliminary work demonstrates that microglial activation measured in the NAWM of MS patients closely correlates to patients' disability evaluated using Expanded Disability Status Scale (EDSS) and age. Importantly, our results suggest a presence of a threshold in the level of TSPO radioligand binding, which segregated the patients within our cohort to RRMS and SPMS clinical subgroups (Rissanen et al., submitted). Giannetti et al. demonstrated that TSPO binding in $\mathrm{T} 1$ black holes of progressive patients may correlate with clinical disability and was predictive of disease progression [47]. However, black holes with smaller volume were shown to have higher TSPO binding compared to larger lesions in RRMS patients and hence this observation might to some extent be due to partial volume effect and should be interpreted with caution.

The conversion of RRMS to SPMS is insidious and may be difficult to determine clinically. At this stage, the patients may experience increasing difficulties with bladder control, spasticity, cognition and weakness. Measuring EDSS has proven to have limited use for prediction of SPMS [68], and the ability of conventional MRI parameters to predict progression of disease is similarly limited [69]. It would be, however, highly important to be able to detect patients on the verge of SPMS to be able to prevent, or efficiently treat SPMS. While increasing atrophy and enlarging black holes can be detected in longitudinal follow-up as MRI signs of progressive disease, the information is inevitably retrospective, whereas treatment decisions aiming to slow down progression need to be done prospectively. Here, TSPO imaging may be of help, as PET enables the detection of microglial activation in the NAWM, an alteration which likely precedes development of gross atrophy and might promptly respond to therapy owing to the highly plastic nature of microglial cells [61]. Hence, it might be possible to use TSPO imaging as a biomarker to help evaluate the MS disease stage and severity, and even to predict the conversion of RRMS to SPMS disease, prior measurable clinical signs of permanent disability have emerged. TSPO imaging might thus help to alleviate the clinico-radiological paradox in MS. Longitudinal studies with clinical follow-up and imaging in same patients are needed to evaluate this further.

TSPO imaging might also be valuable in distinguishing features of focal pathology in SPMS. Neuropathology studies have defined various types of plaques in MS. These can be detected both in the WM and in the GM, and they vary in composition depending on the disease stage [6]. The WM lesions in RRMS are typically of the active-lesion type, and they are likely the pathologic correlate of clinical attacks [5]. In SPMS, the plaques are mostly of the chronic active, slowly expanding (smouldering), or chronic inactive derivatives, with the classification depending on the presence and distribution of macrophages and activated microglial cells in the plaque edge [6]. In our in vivo PET studies of SPMS patients, we demonstrated that TSPO imaging can be used to differentiate the chronic active and chronic inactive plaques also in vivo, a manifestation of microglial cell activation not detectable by MR imaging (Figs. 1, 2). In our cohort of advanced SPMS patients, $57 \%$ of the plaques were of the chronic active type, with increased TSPO binding at the plaque edge [49]. The evaluation of TSPO binding could thus be used for in vivo differentiation between different subtypes of chronic lesions, and its usability as an outcome measure should be tested in treatment studies of progressive disease.
Fig. 1 In vivo differentiation of chronic T1 lesions using TSPOPET. Left image a T1-weighted MRI image with two similarlooking (non-gadoliniumenhancing) T1 black holes. TSPO-PET (on the right) shows that in the upper lesion there is microglial activation, confirming this lesion to be a chronic active lesion, whereas in the lower lesion there is no radioligand uptake, confirming this lesion to be a chronic inactive lesion
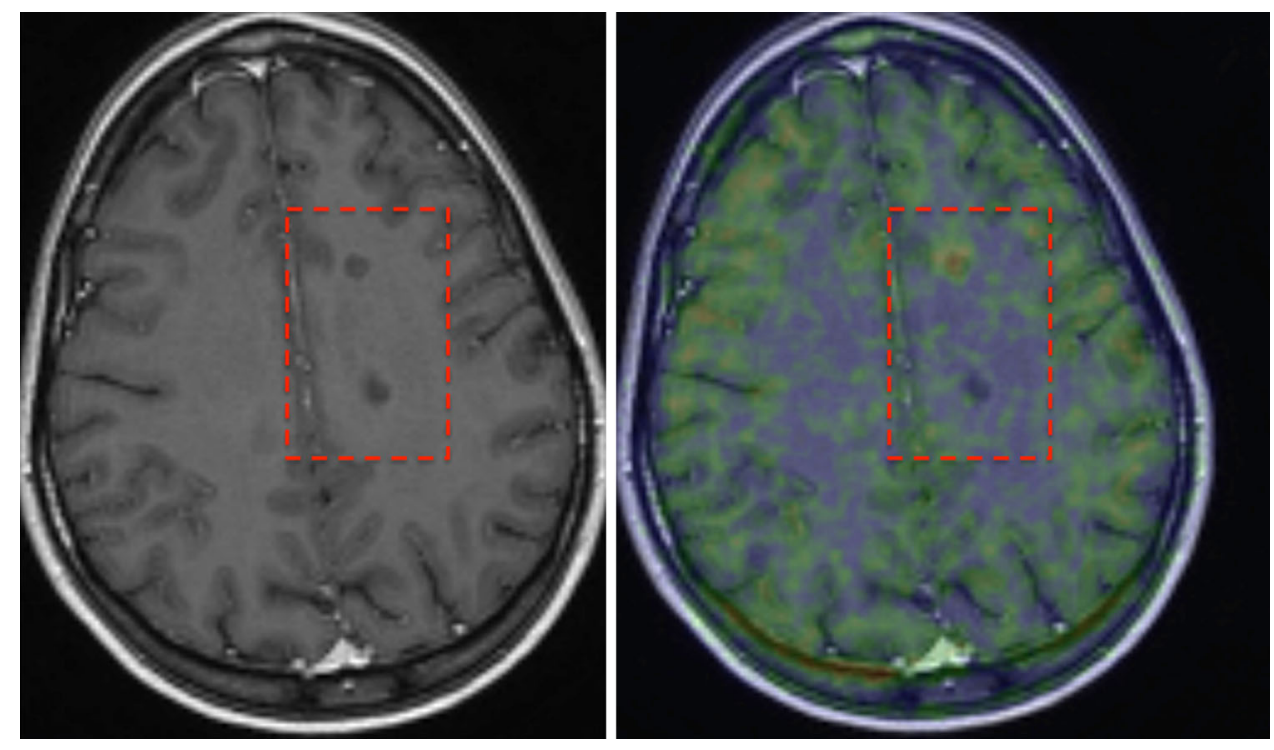


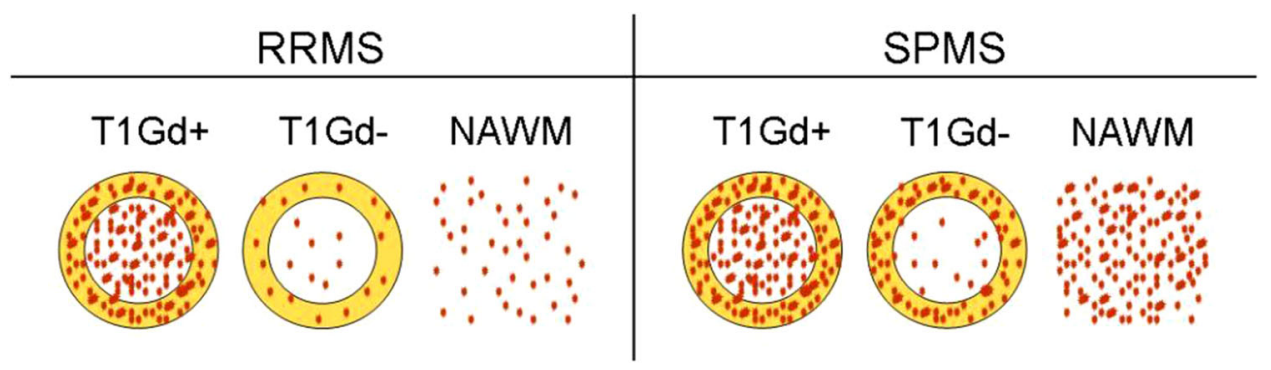

Fig. 2 PK11195 binding patterns in MS. A schematic drawing of PK11195 binding patterns in T1 lesional (centre of the circle) and perilesional (yellow rim of the circle) WM and NAWM in RRMS compared to SPMS. Red dots PK11195 binding as a sign of microglial

\section{Considerations on methodological challenges}

Until today, the methods for the modelling of dynamic brain $\left[{ }^{11} \mathrm{C}\right](\mathrm{R})-\mathrm{PK} 11195$ imaging have varied from study to study due to the lack of harmonisation of protocols. For instance, in some of the earlier studies using $\left[{ }^{11} \mathrm{C}\right] \mathrm{PK} 11195$, cortical gray matter has been used as a reference region, whereas in others it was the main target of interest $[48,57,59]$. The use of a clustered reference region appears to now have established its position in the estimation of specific ligand binding in clinical studies, and there is hope for more homogenous methodology and better comparison of results between different studies [47$49,61]$. It appears likely that reference region clustering could be developed also for second-generation TSPO ligands in future studies. Nonetheless, subtle differences in the results between study groups may arise from differences in image reconstruction protocols and PET scanner features, as well as due to the different methods used for kinetic modelling and ROI acquisition, and for calculating the parametric images (Table 2). In the PET imaging studies of progressive MS, the target of interest is activated microglial cell expressing TSPO (the cell type believed to be related to neurodegeneration). As there is also strong expression of TSPO on endothelial cells, and as the brain is very heavily vascularised, it is a major modelling challenge to omit the blood vessel-derived TSPO signal when using TSPO ligands for evaluating microglial activation. Cortical microglial signal especially can be contaminated by the TSPO signal arising from the large blood vessels close to the cortex. Importantly, attempts have been made to overcome this problem with novel kinetic modelling [70]. Development of improved methods for co-registration of MRI and PET scans and motion correction of PET scans will also help to exclude unwanted signal, and to detect the specific signal of the cell type of interest. Another potential source of biological variance in TSPO studies of MS is activated astrocytes, activation. RRMS = relapsing-remitting multiple sclerosis; SPMS $=$ secondary progressive multiple sclerosis; $\mathrm{Gd}+=$ gadolin ium positive; $\mathrm{Gd}-=$ gadolinium negative; $\mathrm{NAWM}=$ normal appearing white matter

which also express TSPO at least at some circumstances [35]. It would be a major advantage if in the future the different study centres would work together to harmonise and validate protocols for image acquisition, processing and modelling for use in future studies of progressive MS. Another important aspect of the methodological development of MS PET studies is the notion that all novel PET radioligands can presently be evaluated in preclinical models of MS disease before application in (the very expensive) human studies. This pathway has already been used in case of MS and TSPO imaging [71].

\section{Other targets for evaluation of neuroinflammation in MS}

\section{Adenosine A2A receptors}

Adenosine is a ubiquitous purine, which acts by binding to four types of widely expressed G-protein-coupled receptors, namely A1R, A2AR, A2BR, and A3R. Adenosinemediated signalling leads to modulation of inflammation [72], and in the peripheral immune system, especially the A2AR-mediated effects efficiently attenuate inflammation [73]. A2ARs are strongly upregulated at sites of inflammation and tissue damage, thus providing an endogenous way to limit inflammation [74]. In the CNS, the outcome of A2AR-mediated signalling is, however, much less clear [75]. We have studied the NAWM of SPMS patients using PET and a radioligand [11C]TMSX ([7- $N$-methyl-11C](E)-8-(3,4,5-trimethoxystyryl)-1,3,7-trimethylxanthine) binding to A2A receptors, and found increased expression of A2AR in the NAWM of patients compared to controls [76]. Our work demonstrates the potential usefulness of [11C]TMSX-PET imaging in clarifying the diffuse pathologic alterations in the NAWM associated with progressive MS disease. The method could thus complement the TSPO imaging approaches in progressive MS. 


\section{Other targets}

Several other promising targets that have not yet been utilised in MS research have emerged in the field of imaging neuroinflammation. Purinoreceptor P2X7 has been linked to microglia-mediated neuroprotection via activation of the receptors by ATP [77]. Novel P2X7 antagonists have been developed, and are promising candidates for being used as P2X7 PET tracers [78, 79]. Cannabinoid receptor 2 (CB2) is also expressed in activated microglia [80], and consequently, numerous ligands have recently been developed and pre-clinically tested [81-84]. In addition, histamine 4 (H4) and cyclo-oxygenase 2 (COX-2) receptors being involved also in neuroinflammation, and folate receptors being linked to many inflammatory and autoimmune diseases, appear as interesting future targets for PET imaging of neuroinflammation [85-87].

\section{Conclusions}

TSPO-PET imaging has potential for evaluation of MS pathology in vivo in a sensitive and quantifiable way at molecular level, and thus gives added value over conventional MRI. This would be especially useful for evaluation of progressive MS, where TSPO-PET allows detection of diffuse pathology in the NAWM. TSPO-PET could thus potentially be used as an imaging biomarker of diffuse neuroinflammation related to disease progression in MS and could help to identify patients who will soon enter the progressive phase of the disease. This is especially important when striving to develop disease-modifying therapies in progressive MS, where conventional imaging markers are known to correlate inadequately with the clinical phenotype and the prognosis of the disease, and where there is presently a great unmet need [88-90]. Here, TSPO imaging might prove valuable as a surrogate marker. There are, however, still technical challenges, and it is our task in the future to try to harmonise and validate the methodology to be able to perform multi-centre studies using TSPO-PET. This would help to improve the design of future clinical trials and to allow the measurement of the effects of new drugs aimed at reducing neurodegeneration and neuroinflammation contained within the CNS. Further work is needed to understand the TSPO signal in terms of microglial activation phenotype, and to develop new ligands potentially better at distinguishing between different phenotypes.

Acknowledgments We wish to acknowledge all patients who have taken part in the PET imaging studies, and all co-workers who have contributed to the studies. Our funding sources are also acknowledged: Finnish Academy, Finnish MS Foundation and the European
Union's Seventh Framework Programme (FP7/2007-2013) under Grant Agreement No. HEALTH-F2-2011-278850 (INMiND).

Authors' contributions L. Airas: Literature Review, Content planning and Manuscript Writing; E. Rissanen: Literature Search and Review, and Manuscript Drafting; J.O. Rinne: Manuscript Writing and Editing.

\section{Compliance with ethical standards}

Conflict of interest Laura Airas, Eero Rissanen and Juha Rinne declare no conflict of interest.

Human and animal rights The article does not contain any studies with human or animal subjects performed by any of the authors.

\section{References}

1. Compston A, Coles A (2008) Multiple sclerosis. Lancet 372:1502-1517. doi:10.1016/S0140-6736(08)61620-7

2. Costello K, Halper J, Kalb R, Skutnik S, Rapp R (2014) The use of disease-modifying therapies in multiple sclerosis. Principles and current evidence. A consensus paper by the multiple sclerosis coalition. http://www.nationalmssociety.org/getmedia/5ca284d3fc7c-4ba5-b005-ab537d495c3c/DMT_Consensus_MS_Coalition_ color

3. Kutzelnigg A, Lassmann H (2014) Pathology of multiple sclerosis and related inflammatory demyelinating diseases. Handb Clin Neurol 122:15-58. doi:10.1016/B978-0-444-52001-2. 00002-9

4. Kobelt G, Berg J, Lindgren P, Fredrikson S, Jonsson B (2006) Costs and quality of life of patients with multiple sclerosis in Europe. J Neurol Neurosurg Psychiatry 77:918-926. doi:10.1136/ jnnp.2006.090365

5. Lassmann H, van Horssen J, Mahad D (2012) Progressive multiple sclerosis: pathology and pathogenesis. Nat Rev Neurol 8:647-656. doi:10.1038/nrneurol.2012.168

6. Frischer JM, Bramow S, Dal-Bianco A et al (2009) The relation between inflammation and neurodegeneration in multiple sclerosis brains. Brain 132:1175-1189. doi:10.1093/brain/awp070

7. Trapp BD, Nave KA (2008) Multiple sclerosis: an immune or neurodegenerative disorder? Annu Rev Neurosci 31:247-269. doi:10.1146/annurev.neuro.30.051606.094313

8. Trapp BD, Peterson J, Ransohoff RM, Rudick R, Mork S, Bo L (1998) Axonal transection in the lesions of multiple sclerosis. N Engl J Med 338:278-285. doi:10.1056/NEJM199801293380502

9. Ching AS, Kuhnast B, Damont A, Roeda D, Tavitian B, Dolle F (2012) Current paradigm of the $18-\mathrm{kDa}$ translocator protein (TSPO) as a molecular target for PET imaging in neuroinflammation and neurodegenerative diseases. Insights Imaging 3:111-119. doi:10.1007/s13244-011-0128-x

10. Biber K, Owens T, Boddeke E (2014) What is microglia neurotoxicity (Not)? Glia 62:841-854. doi:10.1002/glia.22654

11. Minghetti L, Levi G (1998) Microglia as effector cells in brain damage and repair: focus on prostanoids and nitric oxide. Prog Neurobiol 54:99-125

12. Gao Z, Tsirka SE (2011) Animal models of MS reveal multiple roles of microglia in disease pathogenesis. Neurol Res Int 2011:383087. doi:10.1155/2011/383087

13. McMahon EJ, Bailey SL, Castenada CV, Waldner H, Miller SD (2005) Epitope spreading initiates in the CNS in two mouse models of multiple sclerosis. Nat Med 11:335-339. doi:10.1038/ nm1202 
14. Breij EC, Brink BP, Veerhuis R et al (2008) Homogeneity of active demyelinating lesions in established multiple sclerosis. Ann Neurol 63:16-25. doi:10.1002/ana.21311

15. Magliozzi R, Howell OW, Reeves C et al (2010) A gradient of neuronal loss and meningeal inflammation in multiple sclerosis. Ann Neurol 68:477-493. doi:10.1002/ana.22230

16. Kutzelnigg A, Lucchinetti CF, Stadelmann C et al (2005) Cortical demyelination and diffuse white matter injury in multiple sclerosis. Brain 128:2705-2712. doi:10.1093/brain/awh641

17. Howell OW, Rundle JL, Garg A, Komada M, Brophy PJ, Reynolds R (2010) Activated microglia mediate axoglial disruption that contributes to axonal injury in multiple sclerosis. J Neuropathol Exp Neurol 69:1017-1033. doi:10.1097/NEN. 0b013e3181f3a5b1

18. Gao HM, Hong JS (2008) Why neurodegenerative diseases are progressive: uncontrolled inflammation drives disease progression. Trends Immunol 29:357-365. doi:10.1016/j.it.2008.05.002

19. Papadopoulos V, Baraldi M, Guilarte TR et al (2006) Translocator protein $(18 \mathrm{kDa})$ : new nomenclature for the peripheral-type benzodiazepine receptor based on its structure and molecular function. Trends Pharmacol Sci 27:402-409. doi:10.1016/j.tips. 2006.06.005

20. Casellas P, Galiegue S, Basile AS (2002) Peripheral benzodiazepine receptors and mitochondrial function. Neurochem Int 40:475-486

21. Doble A, Malgouris C, Daniel M et al (1987) Labelling of peripheral-type benzodiazepine binding sites in human brain with [3H]PK 11195: anatomical and subcellular distribution. Brain Res Bull 18:49-61

22. Schoemaker H, Morelli M, Deshmukh P, Yamamura HI (1982) [3H]Ro5-4864 benzodiazepine binding in the kainate lesioned striatum and Huntington's diseased basal ganglia. Brain Res 248:396-401

23. Stephenson DT, Schober DA, Smalstig EB, Mincy RE, Gehlert DR, Clemens JA (1995) Peripheral benzodiazepine receptors are colocalized with activated microglia following transient global forebrain ischemia in the rat. J Neurosci 15:5263-5274

24. Vowinckel E, Reutens D, Becher B, Verge G, Evans A, Owens T, Antel JP (1997) PK11195 binding to the peripheral benzodiazepine receptor as a marker of microglia activation in multiple sclerosis and experimental autoimmune encephalomyelitis. J Neurosci Res 50:345-353. doi:10.1002/(SICI)10974547(19971015)50:2<345:AID-JNR22>3.0.CO;2-5

25. McGeer PL, Itagaki S, Boyes BE, McGeer EG (1988) Reactive microglia are positive for HLA-DR in the substantia nigra of Parkinson's and Alzheimer's disease brains. Neurology 38:1285-1291

26. Gerhard A, Pavese N, Hotton G et al (2006) In vivo imaging of microglial activation with $[11 \mathrm{C}](\mathrm{R})-\mathrm{PK} 11195$ PET in idiopathic Parkinson's disease. Neurobiol Dis 21:404-412. doi:10.1016/j. nbd.2005.08.002

27. Ouchi Y, Yoshikawa E, Sekine Y, Futatsubashi M, Kanno T, Ogusu T, Torizuka T (2005) Microglial activation and dopamine terminal loss in early Parkinson's disease. Ann Neurol 57:168-175. doi:10. 1002/ana.20338

28. Cagnin A, Brooks DJ, Kennedy AM et al (2001) In-vivo measurement of activated microglia in dementia. Lancet 358:461-467. doi:10.1016/S0140-6736(01)05625-2

29. Edison P, Archer HA, Gerhard A et al (2008) Microglia, amyloid, and cognition in Alzheimer's disease: an [11C](R)PK11195-PET and [11C]PIB-PET study. Neurobiol Dis 32:412-419. doi:10. 1016/j.nbd.2008.08.001

30. Broaddus WC, Bennett JP Jr (1990) Peripheral-type benzodiazepine receptors in human glioblastomas: pharmacologic characterization and photoaffinity labeling of ligand recognition site. Brain Res 518:199-208
31. Vlodavsky E, Soustiel JF (2007) Immunohistochemical expression of peripheral benzodiazepine receptors in human astrocytomas and its correlation with grade of malignancy, proliferation, apoptosis and survival. J Neurooncol 81:1-7. doi:10.1007/ s11060-006-9199-9

32. Su Z, Roncaroli F, Durrenberger PF et al (2015) The 18-kDa mitochondrial translocator protein in human gliomas: a $11 \mathrm{C}$ (R)PK11195 PET imaging and neuropathology study. J Nucl Med. doi:10.2967/jnumed.114.151621

33. Banati RB, Myers R, Kreutzberg GW (1997) PK ('peripheral benzodiazepine')-binding sites in the CNS indicate early and discrete brain lesions: microautoradiographic detection of [3H]PK11195 binding to activated microglia. J Neurocytol 26:77-82

34. Banati RB, Newcombe J, Gunn RN et al (2000) The peripheral benzodiazepine binding site in the brain in multiple sclerosis: quantitative in vivo imaging of microglia as a measure of disease activity. Brain 123(Pt 11):2321-2337

35. Cosenza-Nashat M, Zhao ML, Suh HS, Morgan J, Natividad R, Morgello S, Lee SC (2009) Expression of the translocator protein of $18 \mathrm{kDa}$ by microglia, macrophages and astrocytes based on immunohistochemical localization in abnormal human brain. Neuropathol Appl Neurobiol 35:306-328. doi:10.1111/j.13652990.2008.01006.x

36. Maeda J, Higuchi M, Inaji M et al (2007) Phase-dependent roles of reactive microglia and astrocytes in nervous system injury as delineated by imaging of peripheral benzodiazepine receptor. Brain Res 1157:100-111. doi:10.1016/j.brainres.2007.04.054

37. Junck L, Olson JM, Ciliax BJ et al (1989) PET imaging of human gliomas with ligands for the peripheral benzodiazepine binding site. Ann Neurol 26:752-758. doi:10.1002/ana.410260611

38. Banati RB, Goerres GW, Myers R et al (1999) [11C](R)PK11195 positron emission tomography imaging of activated microglia in vivo in Rasmussen's encephalitis. Neurology 53:2199-2203

39. Schweitzer PJ, Fallon BA, Mann JJ, Kumar JS (2010) PET tracers for the peripheral benzodiazepine receptor and uses thereof. Drug Discov Today 15:933-942. doi:10.1016/j.drudis.2010.08.012

40. Banati RB, Middleton RJ, Chan R et al (2014) Positron emission tomography and functional characterization of a complete PBR/ TSPO knockout. Nat Commun 5:5452. doi:10.1038/ncomms6452

41. Kuhlmann AC, Guilarte TR (2000) Cellular and subcellular localization of peripheral benzodiazepine receptors after trimethyltin neurotoxicity. J Neurochem 74:1694-1704

42. Ji B, Maeda J, Sawada M et al (2008) Imaging of peripheral benzodiazepine receptor expression as biomarkers of detrimental versus beneficial glial responses in mouse models of Alzheimer's and other CNS pathologies. J Neurosci 28:12255-12267. doi:10. 1523/JNEUROSCI.2312-08.2008

43. Rojas S, Martin A, Arranz MJ et al (2007) Imaging brain inflammation with [(11)C]PK11195 by PET and induction of the peripheral-type benzodiazepine receptor after transient focal ischemia in rats. J Cereb Blood Flow Metab 27:1975-1986. doi:10.1038/sj.jcbfm. 9600500

44. Tomasi G, Edison P, Bertoldo A et al (2008) Novel reference region model reveals increased microglial and reduced vascular binding of 11C-(R)-PK11195 in patients with Alzheimer's disease. J Nucl Med 49:1249-1256. doi:10.2967/jnumed.108.050583

45. Turkheimer FE, Edison P, Pavese N et al (2007) Reference and target region modeling of [11C]-(R)-PK11195 brain studies. J Nucl Med 48:158-167

46. Yaqub M, van Berckel BN, Schuitemaker A et al (2012) Optimization of supervised cluster analysis for extracting reference tissue input curves in (R)-[(11)C]PK11195 brain PET studies. J Cereb Blood Flow Metab 32:1600-1608. doi:10.1038/jcbfm. 2012.59 
47. Giannetti P, Politis M, Su P et al (2014) Microglia activation in multiple sclerosis black holes predicts outcome in progressive patients: an in vivo [(11)C](R)-PK11195-PET pilot study. Neurobiol Dis 65:203-210. doi:10.1016/j.nbd.2014.01.018

48. Politis M, Giannetti P, Su P et al (2012) Increased PK11195 PET binding in the cortex of patients with MS correlates with disability. Neurology 79:523-530. doi:10.1212/WNL. 0b013e3182635645

49. Rissanen E, Tuisku J, Rokka J, Paavilainen T, Parkkola R, Rinne JO, Airas L (2014) In vivo detection of diffuse inflammation in secondary progressive multiple sclerosis using PET imaging and the radioligand 11C-PK11195. J Nucl Med 55:939-944. doi:10. 2967/jnumed.113.131698

50. Owen DR, Gunn RN, Rabiner EA et al (2011) Mixed-affinity binding in humans with $18-\mathrm{kDa}$ translocator protein ligands. J Nucl Med 52:24-32. doi:10.2967/jnumed.110.079459

51. Owen DR, Yeo AJ, Gunn RN et al (2012) An 18-kDa translocator protein (TSPO) polymorphism explains differences in binding affinity of the PET radioligand PBR28. J Cereb Blood Flow Metab 32:1-5. doi:10.1038/jcbfm.2011.147

52. International HapMap Project. refSNP rs6971 with alleles $\mathrm{C} / \mathrm{T}$ in dbSNP b126

53. Kreisl WC, Jenko KJ, Hines CS et al (2013) A genetic polymorphism for translocator protein $18 \mathrm{kDa}$ affects both in vitro and in vivo radioligand binding in human brain to this putative biomarker of neuroinflammation. J Cereb Blood Flow Metab 33:53-58. doi:10.1038/jcbfm.2012.131

54. Guo Q, Owen DR, Rabiner EA, Turkheimer FE, Gunn RN (2012) Identifying improved TSPO PET imaging probes through biomathematics: the impact of multiple TSPO binding sites in vivo. Neuroimage 60:902-910. doi:10.1016/j.neuroimage. 2011.12.078

55. Lavisse S, Guillermier M, Herard AS et al (2012) Reactive astrocytes overexpress TSPO and are detected by TSPO positron emission tomography imaging. J Neurosci 32:10809-10818. doi:10.1523/JNEUROSCI.1487-12.2012

56. Dickens AM, Vainio S, Marjamaki P et al (2014) Detection of microglial activation in an acute model of neuroinflammation using PET and radiotracers 11C-(R)-PK11195 and 18F-GE-180. J Nucl Med 55:466-472. doi:10.2967/jnumed.113.125625

57. Debruyne JC, Versijpt J, Van Laere KJ et al (2003) PET visualization of microglia in multiple sclerosis patients using [11C]PK11195. Eur J Neurol 10:257-264

58. Debruyne JC, Van Laere KJ, Versijpt J et al (2002) Semiquantification of the peripheral-type benzodiazepine ligand [11C]PK11195 in normal human brain and application in multiple sclerosis patients. Acta Neurol Belg 102:127-135

59. Versijpt J, Debruyne JC, Van Laere KJ et al (2005) Microglial imaging with positron emission tomography and atrophy measurements with magnetic resonance imaging in multiple sclerosis: a correlative study. Mult Scler 11:127-134

60. Ratchford JN, Endres CJ, Hammoud DA et al (2011) Decreased microglial activation in MS patients treated with glatiramer acetate. J Neurol 259:1199-1205. doi:10.1007/s00415-011-6337$\mathrm{x}$

61. Giannetti P, Politis M, Su P et al (2015) Increased PK11195-PET binding in normal-appearing white matter in clinically isolated syndrome. Brain 138:110-119. doi:10.1093/brain/awu331

62. Oh U, Fujita M, Ikonomidou VN et al (2011) Translocator protein PET imaging for glial activation in multiple sclerosis. J Neuroimmune Pharmacol 6:354-361. doi:10.1007/s11481-010-92436

63. Takano A, Piehl F, Hillert J et al (2013) In vivo TSPO imaging in patients with multiple sclerosis: a brain PET study with [18F]FEDAA1106. EJNMMI Res 3:30. doi:10.1186/2191-219X3-30
64. Vas A, Shchukin Y, Karrenbauer VD et al (2008) Functional neuroimaging in multiple sclerosis with radiolabelled glia markers: preliminary comparative PET studies with [11C]vinpocetine and [11C]PK11195 in patients. J Neurol Sci 264:9-17. doi:10.1016/j.jns.2007.07.018

65. Park E, Gallezot JD, Delgadillo A et al (2015) (11)C-PBR28 imaging in multiple sclerosis patients and healthy controls: testretest reproducibility and focal visualization of active white matter areas. Eur J Nucl Med Mol Imaging 42:1081-1092. doi:10.1007/s00259-015-3043-4

66. Collste K, Forsberg A, Varrone A et al (2015) Test-retest reproducibility of [C]PBR28 binding to TSPO in healthy control subjects. Eur J Nucl Med Mol Imaging. doi:10.1007/s00259-0153149-8

67. Colasanti A, Guo Q, Muhlert N et al (2014) In vivo assessment of brain white matter inflammation in multiple sclerosis with $18 \mathrm{~F}$ PBR111 PET. J Nucl Med 55:1112-1118. doi:10.2967/jnumed. 113.135129

68. Skoog B, Tedeholm H, Runmarker B, Oden A, Andersen O (2014) Continuous prediction of secondary progression in the individual course of multiple sclerosis. Mult Scler Relat Disord 3:584-592. doi:10.1016/j.msard.2014.04.004

69. Gajofatto A, Calabrese M, Benedetti MD, Monaco S (2013) Clinical, MRI, and CSF markers of disability progression in multiple sclerosis. Dis Mark 35:687-699. doi:10.1155/2013/ 484959

70. Rizzo G, Veronese M, Tonietto M, Zanotti-Fregonara P, Turkheimer FE, Bertoldo A (2014) Kinetic modeling without accounting for the vascular component impairs the quantification of [(11)C]PBR28 brain PET data. J Cereb Blood Flow Metab 34:1060-1069. doi:10.1038/jcbfm.2014.55

71. Airas L, Dickens A, Elo P et al (2015) In vivo positron emission tomography imaging demonstrates diminished microglial activation after fingolimod treatment in an animal model of multiple sclerosis. J Nucl Med 56:305-310. doi:10.2967/jnumed.114. 149955

72. Blackburn MR, Vance CO, Morschl E, Wilson CN (2009) Adenosine receptors and inflammation. Handb Exp Pharmacol. doi:10.1007/978-3-540-89615-9_8

73. Ohta A, Sitkovsky M (2001) Role of G-protein-coupled adenosine receptors in downregulation of inflammation and protection from tissue damage. Nature 414:916-920. doi:10.1038/414916a

74. Garcia GE, Truong LD, Li P, Zhang P, Du J, Chen JF, Feng L (2008) Adenosine A2A receptor activation and macrophage-mediated experimental glomerulonephritis. FASEB J 22:445-454. doi:10.1096/fj.07-8430com

75. Moreau JL, Huber G (1999) Central adenosine A(2A) receptors: an overview. Brain Res Brain Res Rev 31:65-82

76. Rissanen E, Virta JR, Paavilainen T et al (2013) Adenosine A2A receptors in secondary progressive multiple sclerosis: a [(11)C]TMSX brain PET study. J Cereb Blood Flow Metab 33:1394-1401. doi:10.1038/jcbfm.2013.85

77. Masuch A, Shieh $\mathrm{CH}$, van Rooijen N, van Calker D, Biber K (2015) Mechanism of microglia neuroprotection: involvement of P2X7, TNFalpha, and valproic acid. Glia. doi:10.1002/glia.22904

78. Rudolph DA, Alcazar J, Ameriks MK et al (2015) Novel methyl substituted 1-(5,6-dihydro-[1,2,4]triazolo[4,3-a]pyrazin-7(8H)yl)methanones are P2X7 antagonists. Bioorg Med Chem Lett 25:3157-3163. doi:10.1016/j.bmcl.2015.06.004

79. Janssen B, Vugts DJ, Funke U et al (2014) Synthesis and initial preclinical evaluation of the $\mathrm{P} 2 \mathrm{X} 7$ receptor antagonist [(1)(1)C]A-740003 as a novel tracer of neuroinflammation. J Labelled Compd Radiopharm 57:509-516. doi:10.1002/jlcr.3206

80. Stella N (2010) Cannabinoid and cannabinoid-like receptors in microglia, astrocytes, and astrocytomas. Glia 58:1017-1030. doi:10.1002/glia.20983 
81. Saccomanni G, Pascali G, Carlo SD et al (2015) Design, synthesis and preliminary evaluation of (18)F-labelled 1,8-naphthyridin- and quinolin-2-one-3-carboxamide derivatives for PET imaging of CB2 cannabinoid receptor. Bioorg Med Chem Lett 25:2532-2535. doi:10.1016/j.bmcl.2015.04.055

82. Savonenko AV, Melnikova T, Wang Y et al (2015) Cannabinoid CB2 receptors in a mouse model of abeta amyloidosis: immunohistochemical analysis and suitability as a PET biomarker of neuroinflammation. PLoS ONE 10:e0129618. doi:10. 1371/journal.pone.0129618

83. Slavik R, Grether U, Muller Herde A et al (2015) Discovery of a high affinity and selective pyridine analog as a potential positron emission tomography imaging agent for cannabinoid type 2 receptor. J Med Chem 58:4266-4277. doi:10.1021/acs.jmed chem.5b00283

84. Yrjola S, Sarparanta M, Airaksinen AJ et al (2015) Synthesis, in vitro and in vivo evaluation of 1,3,5-triazines as cannabinoid CB2 receptor agonists. Eur J Pharm Sci 67:85-96. doi:10.1016/j. ejps.2014.11.003

85. Funke U, Vugts DJ, Janssen B et al (2013) (11) C-labeled and (18) F-labeled PET ligands for subtype-specific imaging of histamine receptors in the brain. J Labelled Compd Radiopharm 56:120-129. doi: $10.1002 / \mathrm{jlcr} .3038$

86. Schieferstein H, Ross TL (2013) (18) F-labeled folic acid derivatives for imaging of the folate receptor via positron emission tomography. J Labelled Compd Radiopharm 56:432-440. doi:10.1002/jlcr.3104

87. Tietz O, Marshall A, Wuest M, Wang M, Wuest F (2013) Radiotracers for molecular imaging of cyclooxygenase-2 (COX2) enzyme. Curr Med Chem 20:4350-4369

88. Bakshi R, Thompson AJ, Rocca MA et al (2008) MRI in multiple sclerosis: current status and future prospects. Lancet Neurol 7:615-625. doi:10.1016/S1474-4422(08)70137-6

89. Miki Y, Grossman RI, Udupa JK, Wei L, Polansky M, Mannon LJ, Kolson DL (1999) Relapsing-remitting multiple sclerosis: longitudinal analysis of MR images-lack of correlation between changes in $\mathrm{T} 2$ lesion volume and clinical findings. Radiology 213:395-399

90. Nijeholt GJ, van Walderveen MA, Castelijns JA et al (1998) Brain and spinal cord abnormalities in multiple sclerosis.
Correlation between MRI parameters, clinical subtypes and symptoms. Brain 121(Pt 4):687-697

91. Studholme C, Hill DL, Hawkes DJ (1997) Automated three-dimensional registration of magnetic resonance and positron emission tomography brain images by multiresolution optimization of voxel similarity measures. Med Phys 24:25-35

92. Logan J, Fowler JS, Volkow ND, Wang GJ, Ding YS, Alexoff DL (1996) Distribution volume ratios without blood sampling from graphical analysis of PET data. J Cereb Blood Flow Metab 16:834-840. doi:10.1097/00004647-199609000-00008

93. Gunn RN, Lammertsma AA, Hume SP, Cunningham VJ (1997) Parametric imaging of ligand-receptor binding in PET using a simplified reference region model. Neuroimage 6:279-287. doi:10.1006/nimg.1997.0303

94. Gunn RN, Lammertsma AA, Cunningham VJ (1998) Parametric imaging of ligand-receptor interactions using a reference tissue model and cluster analysis. In: Carson RE, Daube-Witherspoon ME, Herscovitch P (eds) Quantitative functional brain imaging with positron emission tomography. Academic Press, San Diego, pp 401-406

95. Ashburner J (2007) A fast diffeomorphic image registration algorithm. Neuroimage 38:95-113. doi:10.1016/j.neuroimage.2007.07.007

96. Heckemann RA, Keihaninejad S, Aljabar P, Rueckert D, Hajnal JV, Hammers A (2010) Improving intersubject image registration using tissue-class information benefits robustness and accuracy of multi-atlas based anatomical segmentation. Neuroimage 51:221-227. doi:10.1016/j.neuroimage.2010.01.072

97. Rueckert D, Sonoda LI, Hayes C, Hill DL, Leach MO, Hawkes DJ (1999) Nonrigid registration using free-form deformations: application to breast MR images. IEEE Trans Med Imaging 18:712-721. doi:10.1109/42.796284

98. Schmidt P, Gaser C, Arsic M et al (2012) An automated tool for detection of FLAIR-hyperintense white-matter lesions in multiple sclerosis. Neuroimage 59:3774-3783. doi:10.1016/j.neuroimage. 2011.11.032

99. Varga J, Szabo Z (2002) Modified regression model for the Logan plot. J Cereb Blood Flow Metab 22:240-244. doi:10.1097/ 00004647-200202000-00012 